\section{Nicotine, alcohol and drug dependence}

\section{and psychiatric comorbidity}

\author{
Results of a national household survey \\ MICHAEL FARRELL, SAMANTHA HOWES, PAUL BEBBINGTON, \\ TRAOLACH BRUGHA, RACHEL JENKINS, GLYN LEWIS, JOHN MARSDEN, \\ COLIN TAYLOR and HOWARD MELTZER
}

\author{
Background There is a well- \\ recognised relationship between \\ substance use disorders and other \\ psychiatric disorders. This relationship has \\ been well documented in a range of \\ population-based studies.
}

\begin{abstract}
Aims This study aims to report on consumption patterns of and dependence on nicotine, alcohol and non-prescribed drugs and to report on the levels of psychiatric morbidity in these groups.
\end{abstract}

Method A national household study of psychiatric morbidity was conducted in England and Wales. Psychiatric assessment was based on the Clinical Interview Schedule - Revised (CIS-R). Measures of nicotine, alcohol and drug use and dependence were obtained. This paper compares the levels of psychiatric morbidity in the non-dependent and the nicotine-, alcohol- and drug-dependent cases.

Results Twelve per cent of the nondependent population were assessed as having any psychiatric disorder compared with $22 \%$ of the nicotine-dependent, $30 \%$ of the alcohol-dependent and $45 \%$ of the drug-dependent population.

\section{Conclusions There is a clear relationship between dependence on nicotine, alcohol and drugs and other psychiatric morbidity.}

Declaration of interest None. Funding detailed in Acknowledgements.
There is a consistent finding that substance misuse disorders and other psychiatric disorders are strongly correlated with increased levels of service utilisation (Kessler et al, 1997). The combination of a substance use disorder and other psychiatric disorder is recognised to be increasingly common with the increased use of non-prescribed drugs over the past two decades. It seems likely that substance misuse can activate new psychiatric disorders and aggravate current disorders. Comorbidity has significant implications in service delivery (Johnson, 1997).

Having one psychiatric disorder significantly increases the risk of having multiple psychiatric disorders (Kessler et al, 1997). The relationship between psychiatric disorders, substance consumption, misuse and dependence has been the subject of a large-scale epidemiological study (Helzer \& Pryzbeck, 1988; Regier et al, 1990; Robins \& Regier, 1991; Kessler et al, 1994). The issue of comorbidity of substance use disorders and other psychiatric disorders has become a major policy issue (Hall \& Farrell, 1997). The British Psychiatric Morbidity Survey is the largest programme of epidemiological research on the prevalence of psychiatric disorders conducted to date in the UK (Meltzer et al, 1995; Jenkins et al, 1997a,b). The comparison of the prevalence of nicotine, alcohol and drug dependence across prison, homeless and institutional populations is reported elsewhere (Farrell et al, 1998).

\section{METHOD}

\section{National survey methodology}

A national survey of psychiatric morbidity was conducted in Great Britain (Meltzer et al, 1995) to determine the level of major and minor psychiatric morbidity in the population. The sample was drawn to represent all of Great Britain except the Highlands and Islands of Scotland. Private households with at least one person aged
16-64 years were identified. In all, 15765 private households were identified and provided 12370 adults eligible for interview, of whom 10018 were interviewed. Only one eligible adult (i.e. aged 16-64 years) was interviewed in each household, systematically selected by the Kish grid method (Kish, 1965). This is part of a large programme of surveys to estimate levels of psychiatric morbidity in the general population (Jenkins et al, 1997a,b).

\section{Measures of psychiatric morbidity}

The Clinical Interview Schedule - Revised (CIS-R; Lewis et al, 1992) was used to measure levels of psychological morbidity. The Office of Population Censuses and Surveys (OPCS; now named the Office for National Statistics) questions on tobacco and alcohol consumption used regularly in national surveys were included. Added to were measures of alcohol problems used in the US National Alcohol Survey (Hilton \& Clark, 1991), which recorded experiences over the past 12 months. The Diagnostic Interview Schedule (DIS) on nonprescribed drugs (Robins et al, 1981) was adopted as the measure of use of nonprescribed drugs and dependence. Measures for nicotine, alcohol and other drugs met ICD-10 (World Health Organization, 1992) criteria for dependence. The criteria for alcohol dependence required three or more dependence symptoms and were consistent with the criteria for an ICD-10 diagnosis of alcohol dependence. Parallel surveys were conducted on an institutional (Meltzer et al, 1996) and homeless sample (Gill et al, 1996) and also on a prison sample (Singleton et al, 1999). A repeat household survey is currently under way. Logistic regression was conducted to examine the relationship between consumption and dependence on alcohol, nicotine and non-prescribed drugs and psychological morbidity. Psychological morbidity was measured using CIS-R scores, with those scoring above 12 classed as suffering from mixed anxiety and depressive disorder (F41.2). The use of algorithms allowed the ICD-10 diagnosis of anxiety and depressive disorders from the CIS-R.

\section{RESULTS}

\section{Alcohol consumption and dependence}

Of the 10108 subjects interviewed, $80 \%$ had consumed alcohol in the previous 12 
months, with $20 \%$ reporting abstaining from alcohol or only drinking occasionally (less than one unit per week) in the past 12 months. Just under a quarter $(22 \%)$ of subjects were classed as heavy drinkers ( $5 \%$ very heavy), $20 \%$ were moderate drinkers and $38 \%$ were described as light drinkers. Significant gender differences were found in the levels of alcohol consumption: men were more likely to report heavy drinking than women $\left(\chi^{2}=313\right.$, d.f. $=1, \quad P<0.0001)$; conversely, women were more likely to be abstainers or to be occasional drinkers of alcohol compared with men $\left(\chi^{2}=49\right.$, d.f. $\left.=1, P<0.0001\right)$. These data are consistent with the 1993 Health Survey for England for people aged 16-64 years. Alcohol consumption also varied according to age. Heavy drinking was most prevalent among men aged 2534 years, where $35 \%$ were classed as heavy drinkers compared with $15 \%$ of women. The lowest rates of heavy drinking were found among men and women aged 55-64 years.

Overall, $5 \%$ of those interviewed were classed as alcohol dependent. Alcohol dependence varied according to age, gender and consumption levels (Table 1). With regard to gender, $8 \%$ of men and $2 \%$ of women were classified as alcohol dependent. The pattern of drinking was categorised as: light drinkers, 1-7 units/week for women and 1-10 units per week for men; moderate drinkers, 8-14 units/week for women and 11-21 units/week for men; heavy drinkers, $15+$ units/week for women and 22+ units/week for men (this category subdivided into fairly heavy (1525 units/week for women and 22-35 units/week for men), heavy (26-35 units/ week for women and 36-50 units/week for men) and very heavy drinkers ( $\geqslant 36$ units/ week for women and $\geqslant 51$ units/week for men)). Alcohol dependence increased according to consumption levels, rising from $4 \%$ dependent among moderate drinkers to $34 \%$ among the heavy drinkers. Alcohol dependence was most common among the younger age group of 16-24 years.

\section{Drug use and dependence}

Five per cent of all adults interviewed reported having taken an illegal drug. Cannabis was the most commonly used drug $(5 \%)$, followed by stimulants $(1 \%)$ and hallucinogens $(\mathbf{1} \%)$. Rates of heroin, cocaine and amphetamine use were insufficient to allow separate analyses. For the

Table I The relationship between alcohol consumption level, gender and alcohol dependence

\begin{tabular}{lccc}
\hline Alcohol consumption level & $\begin{array}{c}\text { \% Total population } \\
\text { (\% classed dependent) }\end{array}$ & $\begin{array}{c}\text { \% Male } \\
\text { \% classed dependent) }\end{array}$ & $\begin{array}{c}\text { \% Female } \\
\text { (classed dependent) }\end{array}$ \\
\hline Abstainer/occasional drinker & $20(0)$ & $13(0)$ & $26(0)$ \\
Light & $38(1)$ & $34(1)$ & $41(0)$ \\
Moderate & $20(4)$ & $23(6)$ & $17(2)$ \\
Fairly heavy & $12(10)$ & $15(13)$ & $10(6)$ \\
Heavy & $5(20)$ & $8(18)$ & $3(23)$ \\
Very heavy & $5(34)$ & $8(36)$ & $2(29)$ \\
All drinkers & $80(5)$ & $49(8)$ & 51 (2)
\end{tabular}

Light drinkers, I-7 units/week for women and I-10 units/week for men; moderate drinkers, 8-14 units/week for women and II-2I units/week for men; heavy drinkers, 15+ units/week for women and 22+ units/week for men (this category subdivided into fairly heavy (15-25 units/week for women and 22-35 units/week for men), heavy (26-35 units/week for women and $36-50$ units/week for men) and very heavy drinkers ( $\geqslant 36$ units/week for women and $\geqslant 51$ units/week for men)).

Table 2 Use of drugs and drug dependence by age, gender and type of drug

\begin{tabular}{|c|c|c|c|c|c|c|c|}
\hline \multirow{2}{*}{$\begin{array}{l}\text { Type of } \\
\text { drug used }\end{array}$} & \multirow{2}{*}{$\begin{array}{l}\text { Gender of } \\
\text { subjects }\end{array}$} & \multicolumn{6}{|c|}{$\%$ Taking each type of drug (\% dependent), by age group } \\
\hline & & $16-24$ & $25-34$ & $35-44$ & $45-54$ & $55-64$ & All ages \\
\hline \multirow[t]{3}{*}{ Cannabis } & Male & $18(9.2)$ & $8(1.9)$ & $3(1.3)$ & $0(0)$ & $0(0)$ & $6(2.6)$ \\
\hline & Female & $10(3.2)$ & $3(0.9)$ & $\mathrm{I}(0.2)$ & $I(0)$ & $0(0)$ & $3(0.9)$ \\
\hline & All adults & $14(6.2)$ & $6(1.4)$ & $2(0.8)$ & $0(0)$ & $0(0)$ & $5(1.8)$ \\
\hline \multirow[t]{3}{*}{ Other drugs } & Male & $16(6.4)$ & $4(1.3)$ & I (0.4) & $0(0)$ & $0(0)$ & $5(1.7)$ \\
\hline & Female & $4(1.2)$ & $2(1.0)$ & I (0.5) & $0(0)$ & $\mathrm{I}(0.7)$ & $2(0.8)$ \\
\hline & All adults & $10(3.9)$ & $3(1.1)$ & I (0.5) & $0(0)$ & $2(0.5)$ & $3(1.2)$ \\
\hline \multirow[t]{3}{*}{ All drugs } & Male & $19(9.4)$ & $9(2.1)$ & $4(1.4)$ & $\mathrm{I}(0.3)$ & $0(0)$ & $7(2.8)$ \\
\hline & Female & $10(3.8)$ & $4(1.6)$ & $2(0.8)$ & I (0.3) & $\mathrm{I}(0.5)$ & $4(1.5)$ \\
\hline & All adults & $15(6.7)$ & $6(1.9)$ & $3(1.1)$ & I (0.3) & I (0.5) & $5(2.1)$ \\
\hline
\end{tabular}

Subjects may have taken more than one type of drug.

purposes of these analyses, drug types were divided into two groups: the use of cannabis and the use of other drugs, which include stimulants, hallucinogens, hypnotics, opiates and solvents. Subjects may have taken more than one type of drug.

As with alcohol consumption, drug use varied according to age and gender (Table 2 ). Men were significantly more likely to have used an illegal or non-prescribed drug in the past $(7 \%$ compared with $4 \%)$ $\left(\chi^{2}=42.30\right.$, d.f. $\left.=1, P<0.0001\right)$, and the use of drugs was far more common among the youngest age group and declined rapidly with increasing age. For example, $15 \%$ of adults in the age group 16-24 years had used a drug in the past year, compared with only $6 \%$ of those aged $25-34$ years and only $1 \%$ of those aged $45-55$ years.

Similarly, drug dependence varied according to age and gender, with $6.7 \%$ of those aged 16-24 years scoring as dependent compared with $0.5 \%$ of those aged 55-64 years. Men were more likely to score as dependent, with $2.8 \%$ of men classed as drug dependent compared with $1.5 \%$ of women. Dependence also varied according to drug type, with $1.8 \%$ classed as dependent on cannabis and $1.2 \%$ classed as dependent on other drugs (Table 2).

\section{Tobacco consumption and nicotine dependence}

At the time of interview $32 \%$ of those surveyed were current smokers, with $8 \%$ classed as light smokers (less than 10 a day), 13\% moderate smokers (10-20 a day) and $11 \%$ heavy smokers (more than 20 a day). At interview, two-thirds of the sample did not smoke cigarettes, with $47 \%$ having never smoked cigarettes and $22 \%$ classed as 
Table 3 Nicotine consumption levels and dependence by age and gender

\begin{tabular}{|c|c|c|c|c|c|c|c|}
\hline \multirow{2}{*}{$\begin{array}{l}\text { Nicotine } \\
\text { consumption level }\end{array}$} & \multirow{2}{*}{$\begin{array}{l}\text { Gender of } \\
\text { subjects }\end{array}$} & \multicolumn{6}{|c|}{ \% Smoking cigarettes, by age group } \\
\hline & & $16-24$ & $25-34$ & $35-44$ & $45-54$ & $55-64$ & All ages \\
\hline \multirow[t]{3}{*}{ Never or ex-smokers } & Male & 63 & 64 & 69 & 7I & 76 & 67 \\
\hline & Female & 63 & 68 & 69 & 70 & 75 & 69 \\
\hline & All & 62 & 66 & 69 & 71 & 76 & 69 \\
\hline Light & Male & 14 & 8 & 6 & 4 & 5 & 8 \\
\hline \multirow[t]{2}{*}{ ( $<10$ per day) } & Female & 14 & 8 & 7 & 7 & 5 & 8 \\
\hline & All & 14 & 8 & 6 & 6 & 5 & 8 \\
\hline Moderate & Male & 17 & 15 & 10 & 10 & 8 & 12 \\
\hline \multirow[t]{2}{*}{ (10-20 per day) } & Female & 17 & 13 & 12 & II & 12 & 13 \\
\hline & All & 17 & 14 & II & 10 & 10 & 13 \\
\hline Heavy & Male & 6 & 13 & 15 & 15 & II & 12 \\
\hline \multirow[t]{2}{*}{ (over 20 per day) } & Female & 6 & 10 & 13 & II & 9 & 10 \\
\hline & All & 6 & 12 & 14 & 13 & 10 & II \\
\hline
\end{tabular}

All adults smoking cigarettes are classified as nicotine dependent.

ex-smokers. Unlike alcohol and tobacco consumption, among those who smoked there were no gender differences in patterns of cigarette consumption (Table 3 ). However, women were significantly more likely to have never smoked cigarettes $\left(\chi^{2}=79.02\right.$, d.f. $=1$, $P<0.0001)$ and men were significantly more likely to be ex-smokers and have quit smoking at some point in the past $\left(\chi^{2}=70.77\right.$, d.f. $=1, P<0.0001)$. Patterns of cigarette consumption did vary according to age, with the heaviest smoking being most common among men and women aged $25-55$ years.

Regarding dependence on nicotine, anyone who currently smoked cigarettes was classed as dependent, that is, $32 \%$ of the sample $(50 \%$ male and $50 \%$ female). Measures are available to discern the severity of nicotine dependence but this is not explored further here.

\section{Psychiatric morbidity}

A total of $15.5 \%$ of all subjects were scored as having a psychiatric disorder, with $13.5 \%$ having one disorder and $2 \%$ of subjects having two or more disorders. Women were more likely than men to have a disorder, with $17 \%$ of females having one disorder compared with $10 \%$ of men and $2.6 \%$ of females having two or more disorders compared with $1.5 \%$ of men.

\section{Drug, alcohol and nicotine dependence and the increased risk of psychiatric morbidity}

The relationship of drug, alcohol and nicotine dependence to psychological morbidity was dependent populations and $45 \%$ of the drug-dependent population. Significant differences across the groups also were found for the presence of two or more disorders: the highest prevalence rates were among the drug-dependent population, where $12 \%$ were assessed as having two or more disorders, compared with only $1 \%$ of the non-dependent population.

Given that there are significant social and demographic factors associated with drug, alcohol and nicotine dependence and with the presence of psychiatric disorders, a multiple logistic regression was performed to control for these and for other significant factors that may confound the observed association between drug, alcohol and nicotine dependence and psychiatric disorder. The odds ratios (ORs) produced show the increase or decrease in the odds of having a psychiatric disorder that an individual with a particular characteristic had in relation to those in a reference category (for which the OR is 1.00) while taking into account the possible confounding effects of other factors in the model.

The following variables were entered into a regression model where having a disorder $v$. having no other psychiatric disorder was the dependent variable: drug dependence, alcohol dependence, nicotine dependence, age, gender, ethnicity, employment status, marital status, housing tenure and family unit type.

Table 5 shows that dependence on drugs, alcohol or nicotine was associated significantly and independently with having a psychiatric disorder, even after various social and demographic characteristics were controlled for. A respondent's age, gender, marital status, housing tenure, work status, type of work (manual $v$. nonmanual) and dependence on drugs, alcohol

Table 4 Number of psychiatric disorders among non-dependent and nicotine-, alcohol- and drug-

\begin{tabular}{lcccc}
\hline & $\begin{array}{c}\text { \% Nicotine- } \\
\text { \% Non-dependent } \\
\text { population with a } \\
\text { disorder }\end{array}$ & $\begin{array}{c}\text { \% Alcohol- } \\
\text { population with } \\
\text { a disorder }\end{array}$ & $\begin{array}{c}\text { \% Drug- } \\
\text { population with } \\
\text { a disorder }\end{array}$ & $\begin{array}{c}\text { dependent } \\
\text { population with } \\
\text { a disorder }\end{array}$ \\
\hline No disorder & $87.8^{\mathrm{abc}}$ & $77.6^{\mathrm{a}}$ & $70.4^{\mathrm{b}}$ & $54.8^{\mathrm{c}}$ \\
Any disorder & $12.2^{\mathrm{abc}}$ & $22.4^{\mathrm{a}}$ & $29.6^{\mathrm{b}}$ & $45.2^{\mathrm{c}}$ \\
One disorder & $10.9^{\mathrm{abc}}$ & $18.8^{\mathrm{a}}$ & $23.5^{\mathrm{b}}$ & $33.0^{\mathrm{c}}$ \\
Two or more & $1.3^{\mathrm{abc}}$ & $3.6^{\mathrm{a}}$ & $6.2^{\mathrm{b}}$ & $12.2^{\mathrm{c}}$ \\
disorders & & & & \\
\hline
\end{tabular}

Values in the same row and sharing the same superscript differ significantly at $P<0.001$. 
Table 5 Significant odds ratios (OR) associated with having a psychiatric disorder (compared to having no disorder)

\begin{tabular}{|c|c|}
\hline & Adjusted OR \\
\hline Drug dependence & 1.00 \\
\hline \multicolumn{2}{|l|}{ Not drug dependent } \\
\hline Drug dependent & $3.25 * *$ \\
\hline Alcohol dependence & 1.00 \\
\hline \multicolumn{2}{|c|}{ Not alcohol dependent } \\
\hline Alcohol dependent & $2.20 * *$ \\
\hline Nicotine dependence & 1.00 \\
\hline \multicolumn{2}{|c|}{ Not nicotine dependent } \\
\hline Nicotine dependent & $1.60 * *$ \\
\hline Gender & 1.00 \\
\hline \multicolumn{2}{|l|}{ Male } \\
\hline Female & $1.79 * *$ \\
\hline Age (years) & 0.87 \\
\hline \multicolumn{2}{|l|}{$16-24$} \\
\hline $25-34$ & $1.22 *$ \\
\hline $35-44$ & $1.45^{* *}$ \\
\hline $45-54$ & $1.49 * *$ \\
\hline $55-64$ & 1.00 \\
\hline Employment status & 1.00 \\
\hline \multicolumn{2}{|l|}{ Working full time } \\
\hline Working part time & 1.12 \\
\hline Unemployed & $2.11 * *$ \\
\hline Economically inactive & $1.64 * *$ \\
\hline Housing tenure & $0.74 * *$ \\
\hline \multicolumn{2}{|l|}{ Owner-occupier } \\
\hline Renter & 1.00 \\
\hline Marital status & 1.00 \\
\hline \multicolumn{2}{|l|}{ Married } \\
\hline Cohabiting & 1.24 \\
\hline Single & 1.07 \\
\hline Widowed & $1.53^{*}$ \\
\hline Divorced & $1.38^{*}$ \\
\hline Separated & $1.54 *$ \\
\hline
\end{tabular}

Variables entered into the model that were not significantly associated with having a disorder were family unit type, socio-economic group and ethnicity. $* P<0.05 ; * * P<0.001$.

and nicotine all were found to be associated independently with having a disorder. However, the dependence variables showed the strongest association with having a psychiatric disorder. Analyses showed that a drug-dependent subject was about three times more likely to have a disorder compared with a non-drug-dependent subject $(\mathrm{OR}=3.25)$. Alcohol dependence also was associated with increased odds of having a disorder $(\mathrm{OR}=2.20)$, as was nicotine dependence (smoking cigarettes, $\mathrm{OR}=1.60)$.

Table 6 Prevalence of psychiatric disorder types among non-dependent and nicotine-, alcohol- and drugdependent populations

\begin{tabular}{|c|c|c|c|c|}
\hline & $\begin{array}{c}\text { \% Non-dependent } \\
\text { population with } \\
\text { specified } \\
\text { disorder }\end{array}$ & $\begin{array}{c}\text { \% Nicotine- } \\
\text { dependent } \\
\text { population with } \\
\text { specified disorder }\end{array}$ & $\begin{array}{c}\text { \% Alcohol- } \\
\text { dependent } \\
\text { population with } \\
\text { specified disorder }\end{array}$ & $\begin{array}{c}\text { \% Drug- } \\
\text { dependent } \\
\text { population } \\
\text { with specified } \\
\text { disorder }\end{array}$ \\
\hline No disorder & $87.5^{\mathrm{abc}}$ & $77.0^{\mathrm{a}}$ & $69.4^{\mathrm{b}}$ & $52.9^{c}$ \\
\hline $\begin{array}{c}\text { Mixed anxiety } \\
\text { disorder }\end{array}$ & $6.2^{\mathrm{abc}}$ & $10.2^{\mathrm{a}}$ & $9.9 \mathrm{~b}$ & $16.3^{c}$ \\
\hline $\begin{array}{l}\text { Generalised } \\
\text { anxiety disorder }\end{array}$ & $2.4^{\mathrm{abc}}$ & $4 . I^{\mathrm{a}}$ & $5.3^{b}$ & $7.3^{c}$ \\
\hline Depression & $1.2^{\mathrm{abc}}$ & $3.7^{a}$ & $7.3^{b}$ & $9.1^{c}$ \\
\hline Phobia & $0.8^{\mathrm{ac}}$ & $1.5^{\mathrm{a}}$ & $1.0^{\mathrm{b}}$ & $5.4^{c}$ \\
\hline Panic disorder & $0.5^{\mathrm{abc}}$ & $1.5^{\mathrm{a}}$ & $2.7^{\mathrm{b}}$ & $2.5^{c}$ \\
\hline
\end{tabular}

Values in the same row and sharing the same superscript differ significantly at $P<0.001$.

The relationship between drug, alcohol and nicotine dependence and psychiatric disorder was found to hold true according to the type of disorder experienced (Table 6). For mixed anxiety disorders, generalised anxiety disorders, depression and phobic and panic disorders there was a clear association between dependence and nondependence. Across all categories of disorder the prevalence of disorders differed significantly between the non-dependent and the drug-, alcohol- and nicotinedependent populations, with the highest rates of disorder generally reported among the drug-dependent group.

\section{Gender differences}

Significant gender differences were found in the prevalence of psychiatric disorders across all groups except in the drug-dependent population. Females in the non-dependent, nicotine-dependent and alcohol-dependent populations were significantly more likely than males to report the presence of a psychiatric disorder. Among the drug-dependent population, gender differences in psychological morbidity disappear - males and females were equally likely to score as having a disorder. Among subjects scoring positively for two or more disorders in the non-dependent population, females were significantly more likely to report two or more disorders. However, among the nicotine-, alcohol- and drug-dependent populations no gender differences were found in the prevalence of two or more disorders.

\section{DISCUSSION}

There is a growing body of work estimating the overlap in prevalence between nicotine, alcohol and drug dependence and general psychiatric morbidity in both general and clinical populations. The figures in this current survey are consistent with other major epidemiological surveys (Kessler et al, 1994; Merikangas et al, 1998). The higher rate of alcohol dependence in the younger population indicates that less severe dependence is detected in younger drinkers. These findings are very similar to those of the National Comorbidity Survey. Thresholds for dependence in the younger population and reliable measures of severity could help to disentangle some of these findings.

\section{Nature of the relationship between dependence and psychiatric morbidity}

This study shows excess morbidity, with the greatest excess in those who are drug dependent, a stepwise reduction to alcohol and a further reduction for nicotine dependence. There does not appear to be any consensus about the nature of the relationship but a bi-directional model appears to be the most plausible. Currently, premorbid psychological or developmental vulnerability is well described as being associated with early involvement with illicit drug use and similar characteristics are associated with early initiation of nicotine and alcohol consumption. Cumulative 
comorbidity across these substances also is likely to add to the gradient, with high rates of nicotine and alcohol dependence in the drug-dependent population.

There is much interest in the selfmedication hypothesis for the use of a range of psychoactive substances but little empirical data to support such a hypothesis, except possibly for the case of affect regulation and consumption of nicotine (Cooney et al, 1998).

Kessler (1995) reports that affective disorders and anxiety disorders are strongly comorbid and that disorders of a single type are more strongly related to each other than to disorders of another type. Kessler et al (1997) report that the relationship of mood and anxiety disorders with substance use disorders was among the weakest comorbidities. Currently, there is a strong appreciation that there are many complex factors influencing the relationship of different disorders.

Studies that could examine directly the nature of the relationship between substance consumption and psychiatric morbidity ideally require a large population cohort followed from early teens into adulthood so that risk factors and measures of personality and psychological well-being prior to involvement with tobacco, alcohol or other drugs could be measured and longitudinal follow-up might determine the contribution of quantified tobacco, alcohol and other drug consumption and dependence to the evolution of psychiatric morbidity.

Such studies are not currently available, but cross-sectional studies provide some indication of the nature of the relationship. Apart from drug-induced organic psychosis, there are very few conditions that are robustly linked to a specific substance. Most of the reports indicate increased levels of disorders across the whole spectrum of disorders. Some studies have reported increased rates of phobic, agoraphobic and panic disorders in alcoholics (Stockwell et $a l, 1984)$ but the larger population-derived samples do not support this (Kessler et al, 1997). Probably, the most robust association is for bipolar disorder, the presence of which seems to be related clearly to increased rates of alcohol dependence in men.

\section{Generalised increase in psychiatric disorder}

The non-specific nature of the increase in the disorders would lead one to hypothesise

\section{CLINICAL IMPLICATIONS}

Dependence is clearly associated with increased rates of psychiatric disorders; all clinicians assessing individuals with alcohol and drug dependence should screen for other psychiatric disorders.

Smoking nicotine is associated significantly with increased psychiatric disorders. Clinicians need to be more aware of the links between smoking and increased rates of psychiatric disorders.

- Dependence is associated with increased rates of multiple psychiatric disorders, which results in significantly increased rates of service utilisation.

\section{LIMITATIONS}

This cross-sectional study cannot elucidate the nature of the relationship between dependence and other psychiatric disorders.

- The low prevalence of severe mental illness limits the capacity to analyse and discuss the issues of comorbidity and severe mental illness.

- The lack of measures of Axis II disorders limits further important explorations of the relationship between Axis I and Axis II disorders.

MICHAEL FARRELL, MRCPsych, SAMANTHA HOWES, BSc, National Addiction Centre, Institute of Psychiatry, King's College London; PAUL BEBBINGTON, PhD, Department of Psychiatry and Behavioural Science, Royal Free and University College London Medical School; TRAOLACH BRUGHA, PhD, Department of Psychiatry University of Leicester; RACHEL JENKINS, FRCPsych, Institute of Psychiatry, King's College London; GLYNN LEWIS, PhD, Department of Psychological Medicine, University of Wales College of Medicine; JOHN MARSDEN, PhD, COLIN TAYLOR, MSc, National Addiction Centre, Institute of Psychiatry, King's College London; HOWARD MELTZER, PhD, Office for National Statistics, London

Correspondence: Dr Michael Farrell, Senior Lecturer and Consultant Psychiatrist, National Addiction Centre, Institute of Psychiatry and Maudsley Hospital, 4 Windsor Walk, London SE5 8AF, UK. E-mail: m.farrell@iop.kcl.ac.uk

(First received 20 September 2000, final revision I0 May 200I, accepted I7 May 200I)

that much, if not all, of the disorder is related to quantity and frequency of consumption of substances that can give rise to anxiety, dysphoria and related subjective feelings. Some of the clinical studies indicate that complete cessation of substance consumption can be associated with immediate improvement in measures of psychological well-being (Raimo \& Schukit, 1998). However, abstinent alcoholand drug-dependent individuals score higher on measures of anxiety and mood-related disorders than the general population. Such a finding is consistent with raised baseline measures of psychiatric morbidity of at-risk young people but also with the longer term impact of prolonged nicotine, alcohol and drug consumption.

\section{Limitations of the study}

The low prevalence of psychotic disorder and other major mental illness makes analyses and reporting on this type of psychiatric comorbidity difficult. Comorbidity with severe mental illness is a topic of major policy concern and some of the issues need to be clarified in studies of nontreatment populations (Johnson, 1997).

This current study is a large British cross-sectional study that reports elevated rates of non-psychotic disorders, with increasing levels of disorders associated with increasing levels of engagement with tobacco, alcohol and other drugs. Future studies with detailed measures of the severity of alcohol and drug dependence 
would help to elucidate the nature of the relationship between the severity of dependence and the degree and severity of psychiatric disorder. This survey measures Axis I disorders and it is likely that Axis II disorders are linked more strongly with alcohol and drug dependence, both for premorbid risk of involvement and as predictors of the severity of dependence. Axis II disorders have been measured in the repeat survey.

Overall, this cross-sectional study replicates other international studies and demonstrates a strong association between nicotine, alcohol and drug dependence, but the nature of the relationship requires longitudinal studies if it is to be elucidated further.

\section{ACKNOWLEDGEMENTS}

C.T. was supported by funding from the Department of Health's Drug Misuse Research Initiative. The views expressed in this publication are those of the authors and not necessarily those of the sponsors.

\section{REFERENCES}

Cooney, J., Stevens, T. \& Cooney, N. (1998) Comorbidity of nicotine dependence with psychiatric and substance use disorder. In Dual Diagnosis and Treatment. Substance Abuse and Comorbid Medical and Psychiatric Disorders (eds H. R. Kranzler \& B. J. Rounsaville), pp. 223-264. New York: Marcel Dekker.

Farrell, M., Howes, S., Tyalor, C., et al (1998) Substance misuse and psychiatric comorbidity: an overview of the OPCS National Psychiatric Morbidity Survey. Addictive Behaviours, 23, 909-918.
Gill, B., Meltzer, H., Hinds, K., et al (1996) Psychiatric Morbidity Among Homeless People. OPCS Surveys of Psychiatric Morbidity in Great Britain, Report 7. London: $\mathrm{HMSO}$

Hall, W. \& Farrell, M. (1997) Comorbidity of mental disorders with substance misuse. British Journal of Psychiatry, I7I, 4-5.

Helzer, J. E. \& Pryzbeck, T. R. (1988) The cooccurrence of alcoholism with other psychiatric disorders in the general population and its impact on treatment. Journal of Studies on Alcohol, 49, 219-224.

Hilton, M. \& Clark, W. B. (1991) Measuring drinking problems in the 1984 National Alcohol Survey. In Alcoho in America (eds W. B. Clark \& M. E. Hilton). New York: Albany State University of New York.

Jenkins, R., Lewis, G., Bebbington, P., et al (1997a)

The National Psychiatric Morbidity Survey - strategy and methods. Psychological Medicine, 27, 765-774.

_, _ , _ , et al (1997b) The National Psychiatric Morbidity Survey - initial findings from the Household Survey. Psychological Medicine, 27, 775-789.

Johnson, S. (1997) Dual diagnosis of severe menta illness and substance misuse: a case for specialist services? British Journal of Psychiatry, I7I, 205-208.

Kessler, R. (1995) Epidemiology of psychiatric comorbidity. In Textbook in Psychiatric Epidemiology (eds M. Tsuang, M. Tohen \& G. E. P. Zahner). New York: John Wiley.

_ , McGonagh, K. A., Zhao, S., et al (1994) Lifetime and I2-month prevalence of DSM-III-R psychiatric disorders in the United States. Archives of General Psychiatry, 51, 8-19.

_ , Crum, R. M., Warner, L. A., et al (1997) Lifetime co-occurrence of DSM-III-R alcohol abuse and dependence with other psychiatric disorders in the National Comorbidity Study. Archives of General Psychiatry, 54, 313-32I.

Kish, L. (1965) Survey Sampling. Chichester: John Wiley \& Sons.

Lewis, G., Pelosi, A. J., Araya, R., et al (1992)

Measuring psychiatric disorder in the community; a standardised assessment for use by lay interviewers. Psychological Medicine, 22, 465-486.

Meltzer, H., Gill, B., Petticrew, M., et al (1995) The Prevalence of Psychiatric Morbidity Among Adults Living in Private Households. OPCS Surveys of Psychiatric Morbidity in Great Britain, Report I. London: HMSO.

_, Gill, B., Petticrew, M., et al (1996) Economic Activity and Social Functioning of Adults with Psychiatric Disorders. OPCS Surveys of Psychiatric Morbidity in Great Britain, Report 3. London: HMSO.

Merikangas, R. K., Mehta, R., Molnar, B., et al (1998) Comorbidity of substance use disorders with mood and anxiety disorders; results of the international consortium in psychiatric epidemiology. Addictive Behaviours, 23, 893-907.

Raimo, E. \& Schukit, M. (1998) Alcohol dependence and mood disorders. Addictive Behaviours, 23. 933-946; Psychiatry, 38, 38I-389.

Regier, D. A., Farmer, M. E., Rae, D. S., et al (1990) Comorbidity of mental disorders with alcohol and other drug abuse: results from the Epidemiologic Catchment Area Study. Journal of the American Medical Association 264, 25II-25।8.

Robins, L. N. \& Regier, D. A. (1991) Psychiatric Disorders in America: The Epidemiological Catchment Area Study. New York: The Free Press (Macmillan).

_ , Helzer, J. E., Croughan, J., et al (198I) Nationa Institute of Mental Health Diagnostic Interview Schedule: its history, characteristics and validity. Archives of General Psychiatry, 38, 38I-389.

Singleton, N., Farrell, M. \& Meltzer, H. (1999) Substance Misuse Among Prisoners in England and Wales. London: Office for National Statistics.

Stockwell, T., Smail, P., Hodgson, R., et al (1984) Alcohol dependence and phobic anxiety states. II. A retrospective study. British Journal of Psychiatry, 144, $58-63$.

World Health Organization (1992) Tenth Revision of the International Classification of Diseases and Related Health Problems (ICD-10). Geneva: WHO. 